\title{
Digital Image Projection for 3D Ice Crystal Icing Accretion Measurements
}

\author{
Jonathan Connolly *, Matthew McGilvray ${ }^{\dagger}$ and David R. H. Gillespie ${ }^{*}$ \\ University of Oxford, Oxford, OX2 OES, UK \\ Geoff Jones ${ }^{\S}$ and Benjamin Collier ${ }^{\mathbb{I}}$ \\ Rolls-Royce Plc, Derby, DE24 8BJ, UK
}

\begin{abstract}
Numerous turbofan power loss events caused by the ingestion of high altitude ice crystals have been reported, causing significant concern to the aviation industry. In recent years, experiments have been conducted to explore the physics behind the accretion process, with the aim of producing numerical models to predict the ice growth. Validation of such models require accurate measurement of three-dimensional ice accretion profiles in more engine realistic applications. To date multi-camera two-dimensional views and gom scanning has been utilised. This paper details the first application of DIP for measuring the transient growth of three dimensional ice crystal accretion profiles. This uses laser grid patterns projected onto the surface of interest and conventional cameras mounted at a different viewing angle to the laser. This method was tested in an altitude ice crystal tunnel, using a prismatic stator blade test piece. Comparison of the DIP results to traditional backlit views and a commercial scanner showed that it was possible to measure ice crystal icing accretion thickness's with an accuracy of $0.5 \mathrm{~mm}$.
\end{abstract}

\section{Nomenclature}

I $=$ Image focal point (camera)

$\mathrm{L}=$ Projection focal point (laser)

$\eta \quad=$ Horizontal distance between laser and camera

$\mathrm{A}=$ Position of laser dot at reference projection plane position

$\mathrm{B}=$ Position of same laser dot as A, but with an increased projection plane thickness

$\mathrm{C}=$ Position of same laser dot as $\mathrm{A}$, but with a further increased projection plane thickness

$\mathrm{b}=\mathrm{As}$ seen by the camera, point $\mathrm{b}$ is equivalent to $\mathrm{B}$. Therefore, as point $\mathrm{A}$ moves to point $\mathrm{B}$, the camera observes a translation of point $A$ to point $b$

$\mathrm{F} \quad=$ Vertically below $\mathrm{B}$ on reference projection plane

$\lambda=$ Horizontal displacement of laser relative to ideal case of vertically aligned laser/camera

PSD $=$ Particle size distribution

$\gamma \quad=$ Calibration piece translation distance

\section{Introduction}

CINCE the 1990's, over 200 incidents of power loss events induced by the ingestion of high altitude ice crystals have $\checkmark$ been reported [1]. The acknowledged theory is that fully glaciated ice crystals are ingested into the fan of the engine, melt throughout the compressor and cool the warm components in the compressor upon impingement. Once surface temperatures are sufficiently low, ice accretion can form and can lead to power surges, flame outs and downstream blade row damage [1]. This process is commonly known as ice crystal icing, to differentiate it from icing caused by

\footnotetext{
*PhD Student, Department of Engineering Science, Oxford Thermofluids Institute.

$\dagger$ Associate Professor, Department of Engineering Science, Oxford Thermofluids Institute.

$\doteqdot$ Associate Professor, Department of Engineering Science, Oxford Thermofluids Institute.

${ }^{\S}$ Subject Matter Expert - Icing and Inclement Weather, Engine Environmental Protection Team, System Design.

II Ice Crystal Tech Focal, Engine Environmental Protection Team, System Design.
} 
supercooled liquid impinging on sub-freezing components. The events have been analysed in the aim of determining the conditions which caused the events to occur to help inform the communities research [2, 3].

In the past decade, fundamental research has been conducted to help understand the physics involved in ice crystal icing. During these experiments, images of the accretion have been taken to document the level of accretion observed. Early research extracted qualitative data from the images to determine the level of icing severity at a range of conditions [4, 5]. In latter years, more sophisticated imaging techniques have evolved to extract quantitative data. The most commonly used technique utilises back-lit shadography of a two dimensional test article and edge detection algorithms to determine the spatial position of the accretion edge and hence its overall shape [6]-9]. This method has provided essential data for the numerical models produced to date, however, the method assumes that the accretion profile is uniform along the span of the test article, which would only be true for an infinitely long or axisymmetric test piece. In reality, three dimensional flows induced by end wall effects and other non-idealities can lead to a non uniform accretion profile. Unless a very short depth of field can be obtained, backlit shadography generally extracts the largest accretion profile along the span of the test article at each circumferential position. For axisymmetric test-pieces it is possible to rotate the object on its major axis, record the edge profile at each rotated position and merge these profiles to produce a full three-dimensional model of the ice accretion. This method has been successfully employed by Currie et al. [10], but is only applicable to axisymmetric geometries, not commonly found in engine realistic components.

For more advanced analysis of test data and validating three dimensional numerical models, a three dimensional accretion thickness needs to be measured. The method needs to be non-intrusive and be able to record live during the experiment (i.e not require re-working of the ice post test, generally involving rapid freezing of the ice to increase its opacity). In machine vision, stereoscopic imaging has been utilised to obtain three dimensional images using two independent cameras. Both cameras image the same object, but are offset and angled relative to each other. This methodology dates back to the second world war in which image pairs were used to view three dimensional images of the enemy zones. To determine depth information, known objects need to be compared between both image data sets. The comparison of both data sets to find commonality, known as the correspondence problem, is a difficult procedure and is especially difficult for moving objects, which is the case for dynamic ice accretion analysis.

To aid this problem, it is common to overlay a pattern onto the object being measured. This allows for automated algorithms to more easily cross compare datasets over the temporal morphing of the imaged object. Salvi et al. found that one of the cameras could be replaced by a projector [11]. This method has previously been used to measure water transport over an airfoil [12] using their own optical system and to supercooled liquid droplet icing on a wind turbine blade using a commercially available system [13]. To the authors knowledge, this type of optical measurement has not yet been applied to ice crystal icing.

In this paper, this method will be referred to as Digital Image Projection (DIP). This paper will explain the details of how the method operates and is calibrated for non planar objects. Results are then shown for a compressor stator airfoil test-piece and compared to a backlit shadography dataset and a further validation dataset produced by a commercial hand-held scanner.

\section{Digital Image Correlation}

Figure 1 shows an idealised DIP system. The laser has a focal point L (position where all laser ray lines diverge from), and the camera has a focal point I. The horizontal separation between the camera and projector is defined as $\eta$ and the vertical height of the projector/laser from the projection place as $\lambda$. For clarity only a single node of the projection array is shown in the diagram. When this node is projected onto a reference plane it is positioned at point A. When a thickness of ice is present above the projection screen, the node originally located at A moves to point $\mathrm{B}$, and again to $\mathrm{C}$ with further accretion. From the perspective of the camera, when the node moves spatially from point $\mathrm{A}$ to $\mathrm{B}$, the camera observes a translation of the node from point $A$ to $b$. Point $F$ is defined as the point vertically below $B$ on the projection plane. The goal of this method is to determine ice thickness, $\overrightarrow{F B}$, by measuring the displacement of projection nodes, $\overrightarrow{A b}$. From similar triangle relationships, the ratio between $\overrightarrow{A b}$ and $\overrightarrow{F B}$ can be related to geometrical parameters of the relative positions of the camera and projector and the ice thickness (Eq. 11. By re-arranging Eq. 11, the relationship between ice thickness, $\overrightarrow{F B}$ and node displacements, $\overrightarrow{A b}$ can be calculated by Eq. 2 A similar analysis can also be performed for when the camera and projector are not vertically aligned. 


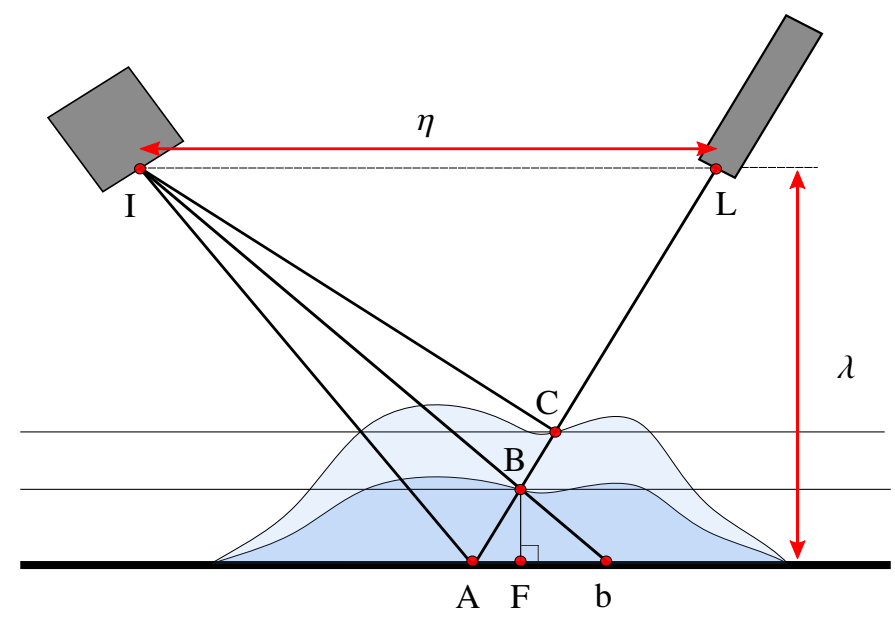

Fig. 1 Relative position of imaging plane (I), projector (P), projector node position at three heights (A,B,C), and equivalent imaging position (b).

$$
\begin{aligned}
& \frac{\overrightarrow{A b}}{F B}=\frac{\eta}{\lambda-\overrightarrow{F B}} \\
& \overrightarrow{F B}=\frac{\frac{\lambda}{\eta} \overrightarrow{A b}}{1+\frac{\overrightarrow{A b}}{\eta}}=\frac{\lambda}{\eta} \overrightarrow{A b}-\frac{\lambda}{\eta^{2}} \overrightarrow{A b}^{2}+\frac{\lambda}{\eta^{3}} \overrightarrow{A b}^{3}-\frac{\lambda}{\eta^{4}} \overrightarrow{A b}^{4}+\ldots
\end{aligned}
$$

A system with a single laser and single camera has inherent limitations on the shapes which it can accurately measure. If there is complex accretion such as in Fig. 2 where there are overhanging regions, for a given laser position it can only capture a certain subset of the accretion edge. For example, in Fig. 2, only the top surface over the overhang will be captured, and the inner surface will be omitted from the measured accretion profile. This will lead to a over-predicted accretion volume. Alternatively, there may be large scale changes in surface topology along the accretion such as shown in Fig. 3 . In this condition, the laser path is not blocked by the ice, however the light path from the laser reflection to the camera is blocked by an adjacent large scale accretion site. The calibration between $\overrightarrow{A b}$ and $\overrightarrow{F B}$ will not have taken the diffraction through the adjacent ice into account, meaning that the true ice thickness will not be accurately measured.

To minimise these effects a traversable laser/camera system, or multiple static laser/camera systems can be utilised. Algorithms can detect when false measurements are taken and only use data from the other datasets. For a single laser/camera system, the devices need careful positioning to minimise these effects for the expected accretion profile topology.

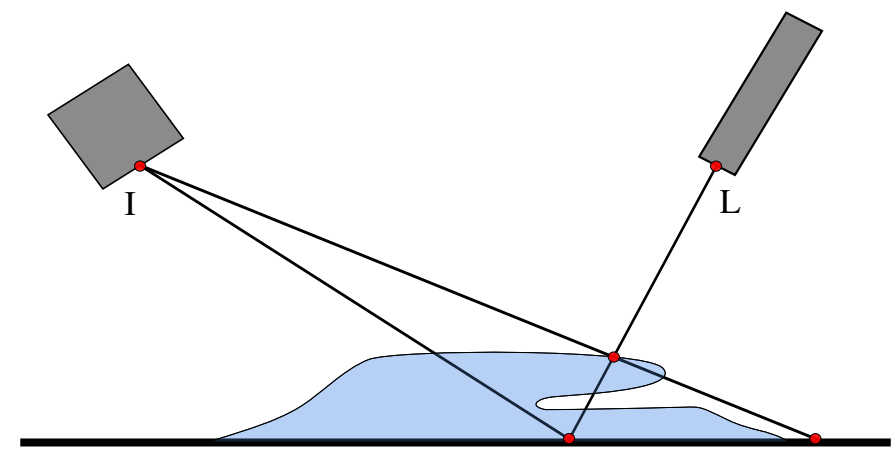

Fig. 2 Over-hanging ice surface which cannot be measured using a single, static laser. 


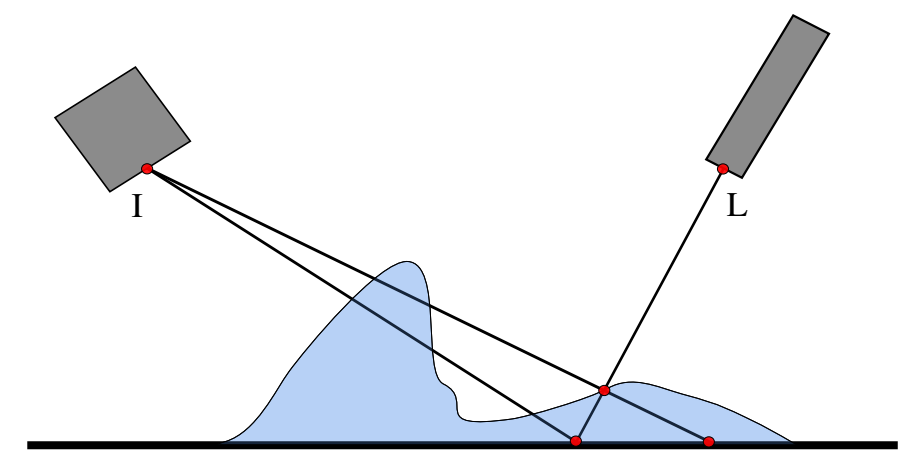

Fig. 3 Adjacent ice peaks to the laser node blocking the optical path of the camera view, leading camera light diffraction - unaccounted for in the calibration.

\section{Experimental}

\section{A. Test Facility}

Experiments were performed within the Research Altitude Test Facility (RATFac) at the National Research Council of Canada (NRC), Ottawa. The altitude chamber is partitioned into a "cold" section and a "warm" section. Ice is initially ground to a specific particle size distribution (PSD) in the "cold" section, and then passed through the ice injection pipe into the "warm" section. The free jet of air and ice crystals pass into the bellmouth of the cascade rig which houses the test piece being analysed. The "warm" section has controllable total pressure, total temperature and humidity, generating engine realistic conditions. More detail of the test facility can be found in [14 16$]$.

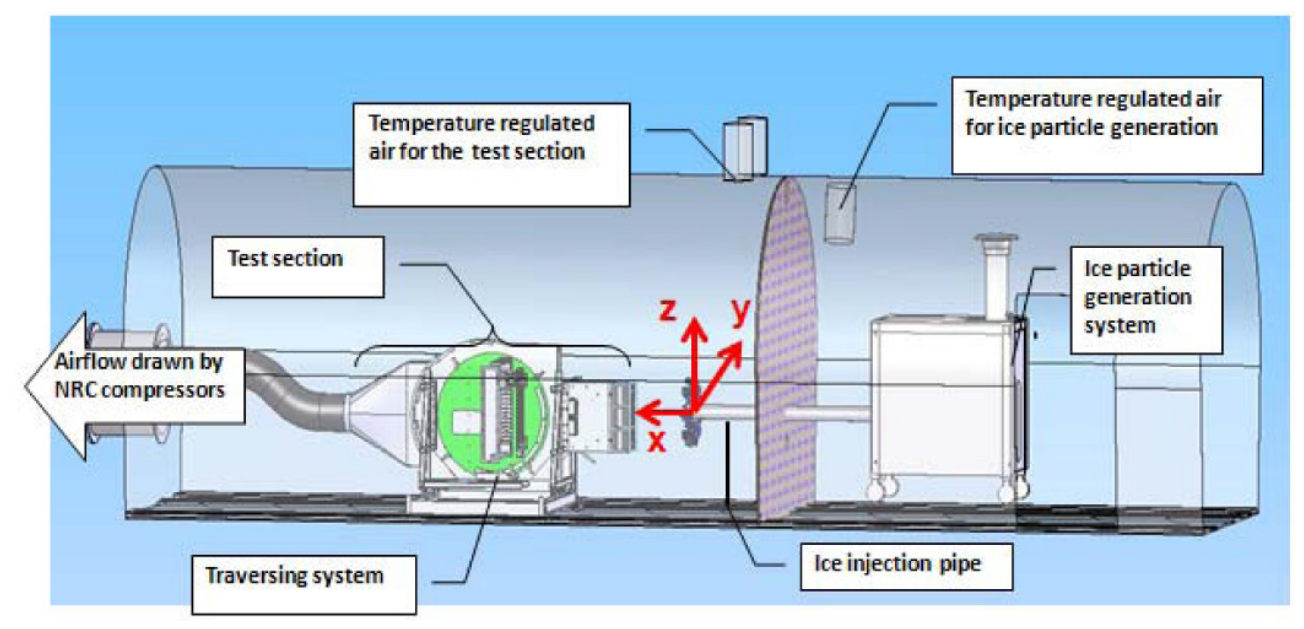

Fig. 4 RATFac altitude chamber, housing the cascade configuration of the icing tunnel [15].

\section{B. Test Conditions}

During the experimental testing, a total of 16 test runs were completed. All test points were nominally set at a total pressure of $34.5 \mathrm{kPa}(27,000 \mathrm{ft})$ and total temperature of $10^{\circ} \mathrm{C}$. Due to limitations in the fine control of tunnel valves, the actual total temperature in the tunnel varied between $10-12^{\circ} \mathrm{C}$ but remained constant for each test point.

Steam injection was controlled inside the chamber to adjust the relative humidity between $30-50 \%$. The ice crystals were ground to have the same particle size distribution for all tests. The cloud distribution was analysed using Particle Image Velocimetry (PIV), and it was found that the cloud had a $D_{v_{10}}, D_{v_{50}}$ and $D_{v_{90}}$ of 18,32 and $54 \mu \mathrm{m}$ respectively. All tests had a total ice content of $4 \mathrm{gm}^{-3}$, which was fully glaciated at the exit of the ice injection pipe. As the crystals propagated through the "warm" section of the chamber, the crystals naturally melted. At the test section, it was measured that the average melt ratio of the crystals varied 5-15\%. All tests were conducted at a Mach number of 0.4 , creating a 
Table 1 Tunnel conditions for each test point analysed.

\begin{tabular}{ccccc}
\hline \hline Test \# & Angle of Attack & RH_0 & TWB & MR \\
\hline 1 & $-1.5^{\circ}$ & $35 \%$ & $1.0^{\circ}$ & 6.8 \\
2 & $0^{\circ}$ & $40 \%$ & $1.4^{\circ}$ & 7.5 \\
3 & $+1.5^{\circ}$ & $38 \%$ & $1.2^{\circ}$ & 7.1 \\
\hline \hline
\end{tabular}

dynamic pressure of $3.46 \mathrm{kPa}$. This paper will analyse the results of three test points from the experiment. The actual conditions for each test is shown in Table 1 .

\section{Test Piece}

The ice thickness was measured on on an un-ducted cantilevered stator blade as shown in Fig. 5 and disused in more detail in [9]. The stator is representative of that found in an intermediate pressure compressor, but was heavily simplified to be vertically stacked. Previous research by Bucknell et al. [9] studied this test piece, and measured the ice thickness by using backlit shadography viewing down the axis of the blade span. This method relies on the assumption that the accretion is uniform along the span. Data from this test piece has been used in validation of the ice crystal icing numerical code ICICLE, produced by the university of Oxford [17]. In reality, the tip gap on the stator will have produced 3D flow effects in this region, potentially causing non-uniformities in accretion levels.

At a non-zero aerodynamic angle of attack, increased aerodynamic forces are applied to the stator. Because the stator was not in a cascade configuration, highly separated flow occurred off the suction surface, causing unsteady aerodynamic loading leading to vibrations. The vibrations cause the DIP system to observe an non-physical oscillating ice thickness. To minimise this effect, the stator was set close to the aerodynamic zero angle of attack and video frames were time averaged over a period of two seconds so that the vibration of the nodes could be analysed as stationary. For the growth rates observed in this experiment, the change in accretion profile over a two second period was found to be insignificant.

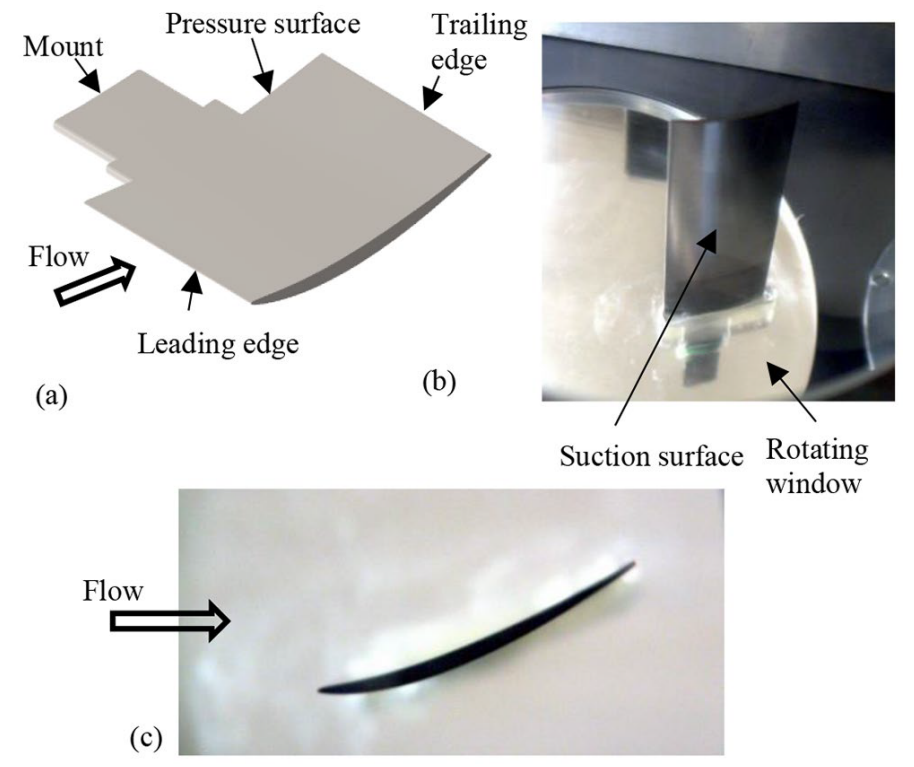

Fig. 5 (a) Isometric view of stator test article; (b) suction surface view; (c) side (tip) view of the stator installed in RATFac. Flow is left to right in all images [9].

\section{Optical Equipment}

An array of dots were projected onto the test piece using a $632 \mathrm{~nm}, 5 \mathrm{~mW}$, Flexpoint ${ }^{\circledR}$ laser produced by Laser Components. A diffractive optical element (DOE) was placed on the front of the laser module to produce a dot array 


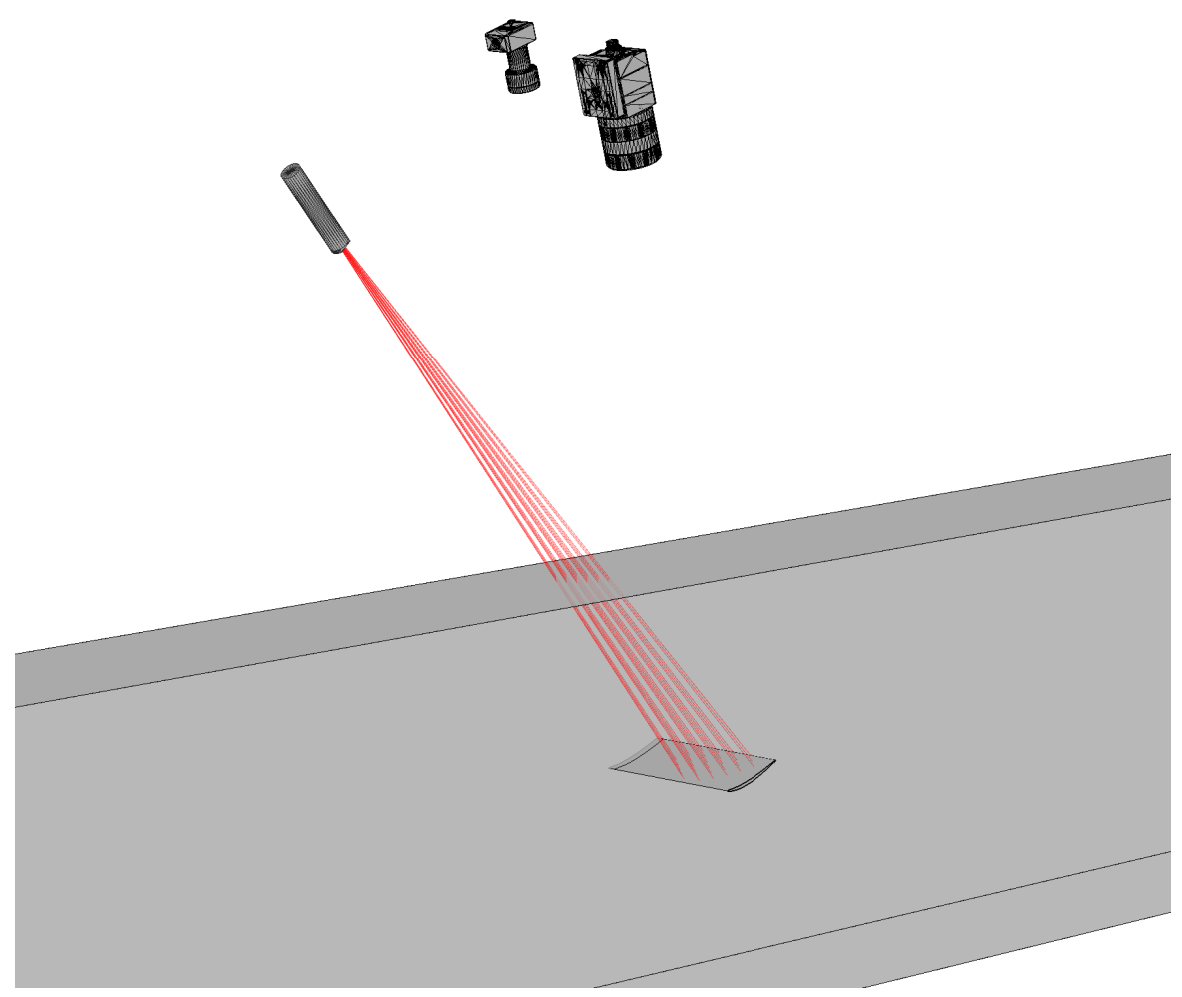

Fig. 6 Positions of laser and cameras relative to the stator.

from the single laser beam. For this experiment, an array of $6 x 6$ nodes was chosen which covered near full chord, and part span of the stator. The array of dots were recorded using 5 MP miniature cameras produced by Ximea, specifically models MU9PM-MH for low speed image capture (5 fps) and MC050MG-SY for a higher frame capture (70 fps).

Figure 6 shows the relative positions of the stator, cameras and laser. The larger camera was the higher frame rate camera, used for all tests. As discussed later, the second smaller camera was also used on some test points to produce a second dataset to improve the accuracy of the system. Figure 7 shows a visual representation of where nodes were positioned on the stator prior to ice accretion. To minimise the computational power required to compute the three dimensional accretion profiles, it was decided to use a coarse $6 \times 6$ grid. The $6 \times 6$ grids commercially available were all square in shape and the maximum spreading angle available produced a projection which covered the whole chord and part span of the blade. The area nearer the free end was deemed more interesting than the cantilevered end due to end walls generally producing gross unrealistic accretion in that region.

\section{E. Calibration Procedure}

The ice thickness can be calculated once the parameters $\eta, \lambda$ and node displacements $(\overrightarrow{A b})$ are known. Practically it is difficult to measure the distances $\eta$ and $\lambda$ to a high level of accuracy especially when projected onto curved surfaces, and they cannot be directly measured if the laser/camera light diffracts through a window. For the experiments shown in this paper, the positions of the camera and projector remained fixed, meaning that the parameters $\lambda$ and $\eta$ were time invariant for each node in the array.

If the reference projection plane is translated vertically by known distances (i.e. the distance $\overrightarrow{F B}$ is known), and the translations $\overrightarrow{A b}$ are measured then non-linear curve fitting can be applied to determine $\lambda$ and $\eta$ without prior knowledge of the exact camera/projector positioning. The formula for $\overrightarrow{A b}$ (Eq. 22) is an infinite order polynomial, but the high order terms become negligible, and so the necessary order of the polynomial needed to be determined.

The test piece used in this study had a camber to its surface, meaning that it was more suitable to use a calibration piece of the same curvature of the stator. This calibration test piece was then translated at an angle of the angle of attack relative to the vertical through a known distance $(\overrightarrow{F B})$, while measuring translation $(\overrightarrow{A b})$ to obtain the coefficients $\eta$ and $\lambda$. For the geometry used in this experiment, it was found that after the $5^{\text {th }}$ order, the output had converged, 


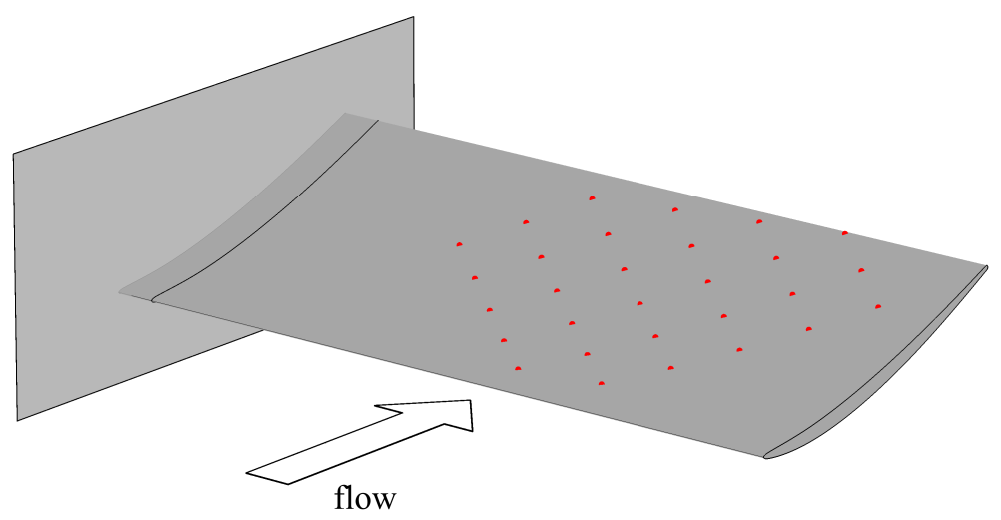

Fig. 7 Initial node positions.

with less than $1 \mu \mathrm{m}$ change with increasing polynomial orders. It was decided to use a 6th order polynomial fit to ensure a realistic fit to the data, while minimising computational resources. Figure 8 shows the non-linear fit between the measured node displacements and known heights for a given node on the projection surface, where the R-Square value was found to be 0.9993 . The spatial coefficient $(\mathrm{K})$, is defined as $\lambda$ divided by $\eta$, equal to the coefficient of the linearised system. Figure 9 shows the variation of $\mathrm{K}$ over the projection surface using the camera/laser positions during the experiments. Due to distortions in the camera lens and the curvature of the test piece, the value of $\mathrm{K}$ varied for each node on the projection surface.

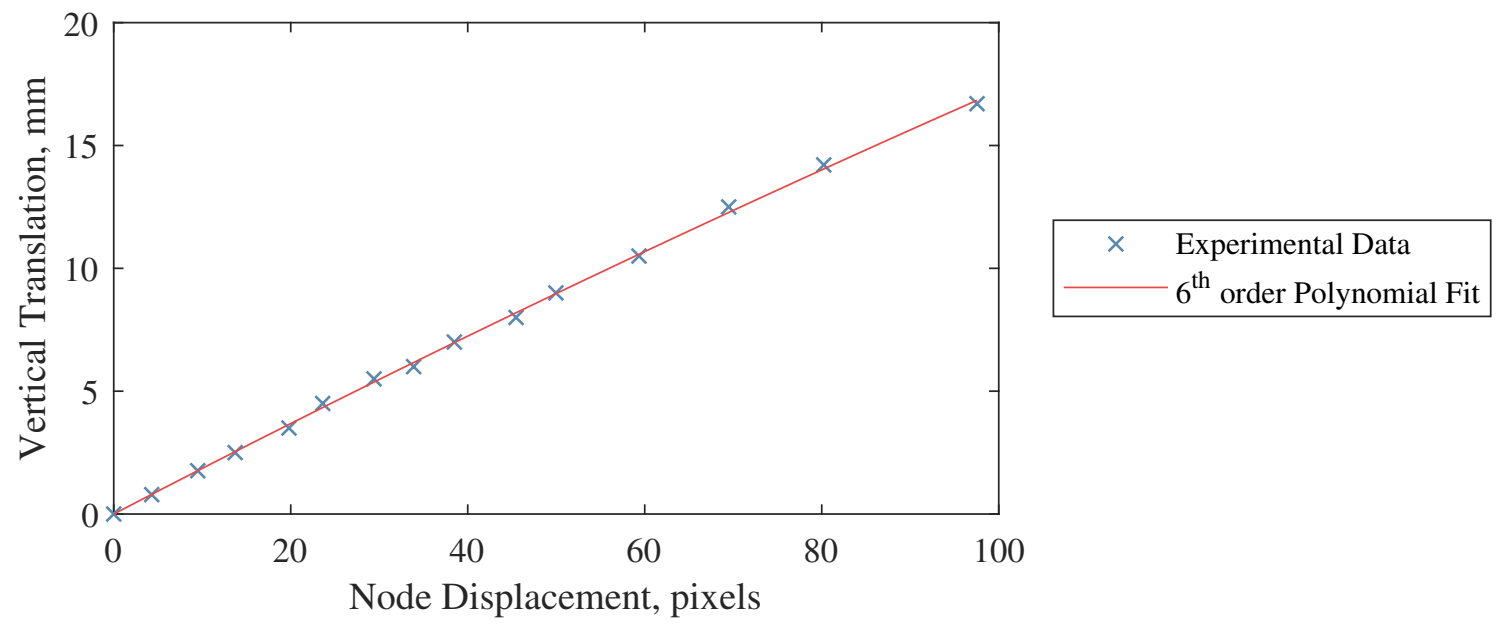

Fig. 8 Experimentally determined node displacements at known heights (blue cross), 6th order polynomial fit (red line).

From the experimental data, for each node the displacement from its initial position was measured, and applying the calibration produced the equivalent displacement distance of the calibration piece for the given node displacement (shown as $\gamma$ in Fig. 10. Because the laser was not aligned with the vertical direction, when the calibration piece was translated, the new node position was no longer vertically above its initial location. Back-tracing the laser ray from its initial location on the stator and finding its intersection with the calibration piece at the known calibration translation $(\gamma)$, the new node position was found.

This method required accurate ray angles for each node. During the experimental set-up the spatial position of the laser was measured relative to the stator blade, and the node positions on the stator were recorded, meaning that the start and end points of the laser rays were known. Diffraction of the laser light through the wind tunnel window meant that the ray angles were unknown. They were found by optimising the ray angles so that the rays diffracted through the window (of known diffractive properties) and intersected the stator at the correct positions. The initial optimisation used the measured laser position, which assumed that the focal point of the laser was located at the end face of the laser, whereas 


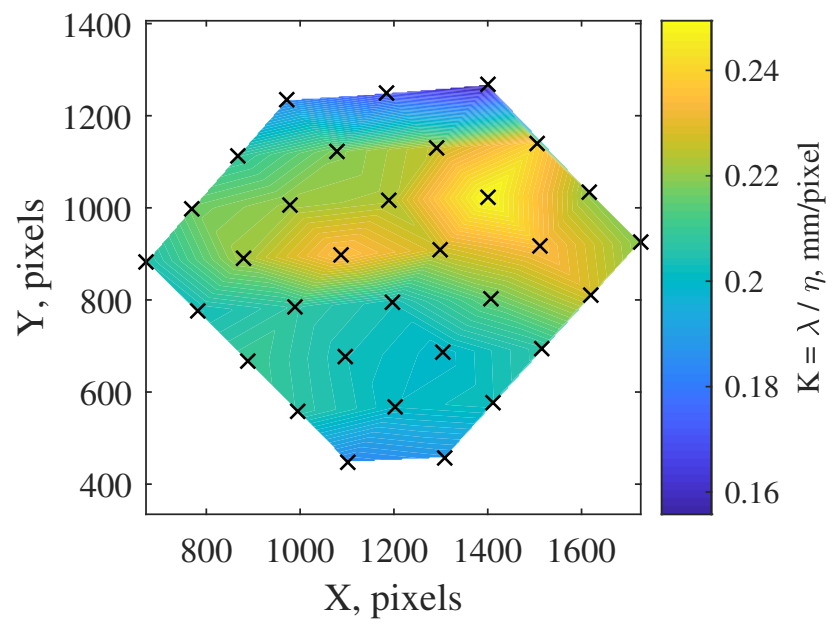

Fig. 9 Contour plot of the ratio of spatial coefficient, $\mathrm{K}$, as determined experimentally. Cross markers show the position of each projection node.

in reality it would have been a few millimetres towards the rear. Because the node positions were monitored during the calibration procedure and hence were known for different positions of the stator, it was possible to then optimise the laser position so that the nodes matched the experimental values for constant ray angles and changing stator positions.

Due to the calibration test piece not having an extended leading edge, nodes in the leading edge region were lost off the calibration test piece when it was vertically translated, as shown in Fig. 10. For these nodes, an incomplete calibration dataset was obtained so these nodes were not used in the following analysis.

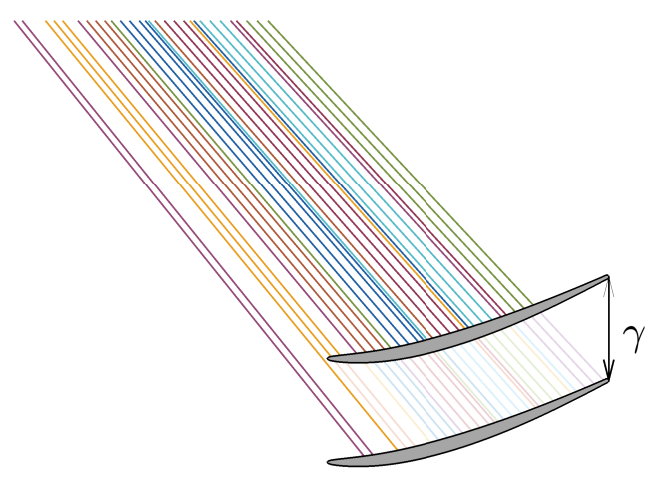

Fig. 10 Ray trace onto calibration test piece, translated by distance $\gamma$. Shown for zero angle of attack.

\section{Results}

Frames were extracted from the DIP video camera at intervals of approximately 30 seconds, analysed and compared to data from a side on backlit camera view. The cameras viewed through windows over which ice passed, meaning that ice periodically stuck to the window, blocking optical access before the ice then shed away. Frames for DIP analysis were chosen such that there was a clear view of the test piece. The data produced from the DIP system was compared to a backlit camera view down the span axis of the stator blade, as shown in Fig. 111 In this figure, the blue line shows the extracted profile from the side view. The laser light was continuously projected onto the test piece, with some light reflecting off the top surface and the rest propagating through the ice layer. This caused the ice accretion to glow a red colour, and this incidentally improved the contrast between the accretion profile and the background, allowing the accretion profile to be more easily extracted from the image.

Previous work [6-9] used this type of view to measure the thickness of the ice, while making the assumption that 


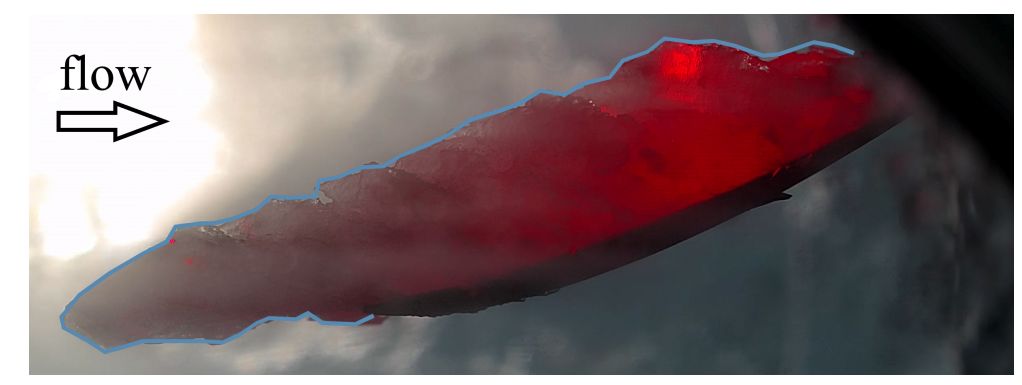

Fig. 11 Side on backlit accretion profile, viewed down the span axis. Image taken after 185 seconds of accretion of Test \# 3.

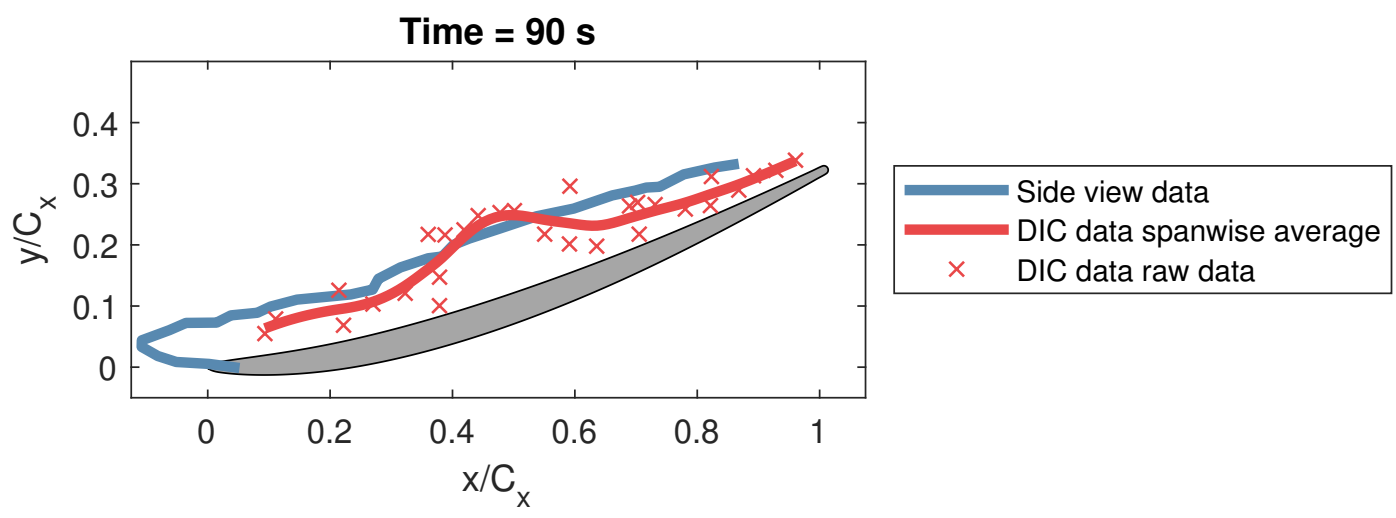

Fig. 12 Side view and DIP data accretion profiles at small accretion levels for Test \# 2.

there was a uniform ice thickness along the viewing axis of the camera. This dataset was used to pseudo-validate the DIP data. It cannot be taken as a "true" measurement of the ice thickness, but was the most accurate widely adopted method for ice measurement during the test.

Figure 12 shows the accretion profile after 90 seconds for test \# 2 (angle of attack of $0^{\circ}$ ). When there was small levels of accretion, there was relatively poor agreement between the side view data and the DIP data. This can be explained due to two reasons. Firstly, the accretion profile which the side on camera observes, is that of the maximum accretion along the span of the blade. After 90 seconds of accretion at this test point, ice had accreted more heavily at the cantilevered end than the free end of the stator. An isometric camera view of the accretion after 90 seconds is shown in Fig. 13 Overlayed on-top of this image is the extracted accretion profile from the backlit shadography (projected onto the isometric frame of reference) and also the pressure surface profile of the clean stator at the side wall intersection. While this view is not a perfect visualisation, it gives insight into the non uniform thickness of ice over the stator, with thicker ice at the fixed end than the mid span or free end during the initial stages of accretion. Because the DIP was only recording data in a region closer to the free end, it captured a lower value of ice accretion thickness compared to the backlit dataset.

At small accretion levels, the laser light has to travel a smaller distance through the ice to reach the underlying metal surface. If a significant amount of laser light reaches the metal surface then a large amount of light scattering occurs which makes it more difficult to identify the node reflected from the top surface of ice. This causes further error in the measurements at small accretion levels, but its effect was minimal once larger amounts of accretion had occurred due to less light reaching the metal surface.

Figures 14 to 16 show the accretion profiles from the three test cases at four moments in time. After the initial transient growth of ice along the span of the stator, better agreement was observed between the DIP data and the side on camera. It can be seen that there is scatter in the DIP data, implying that there are spanwise variations in accretion thickness, which previously could not be quantitatively measured.

The remainder of the analysis in this paper focusses on Test \# 1 . To further quantify the accuracy of the DIP data, 


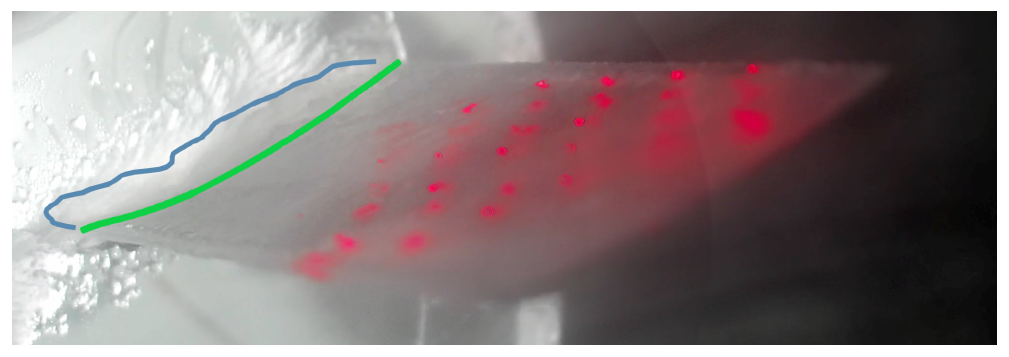

Fig. 13 Accretion after 90 seconds for Test \# 2. Profile from backlit shadography is shown in blue, and the underlying stator profile shown in green.
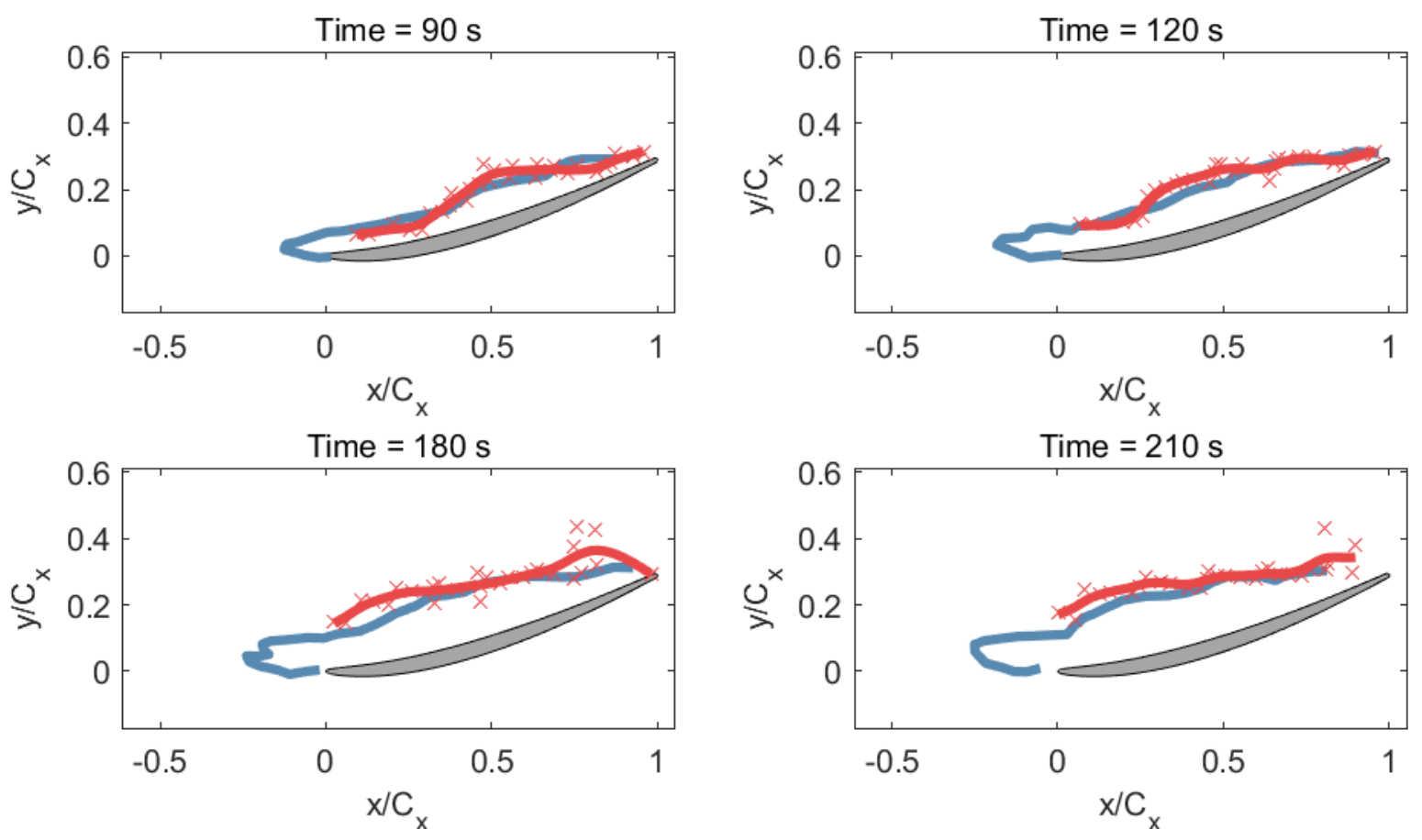

Fig. 14 Test \# 1: $-\mathbf{- 1 . 5}^{\circ}$ Angle of Attack. Side view camera data shown in blue, individual DIP node data in red crosses, and spanwise averaged DIP data shown in red line. 

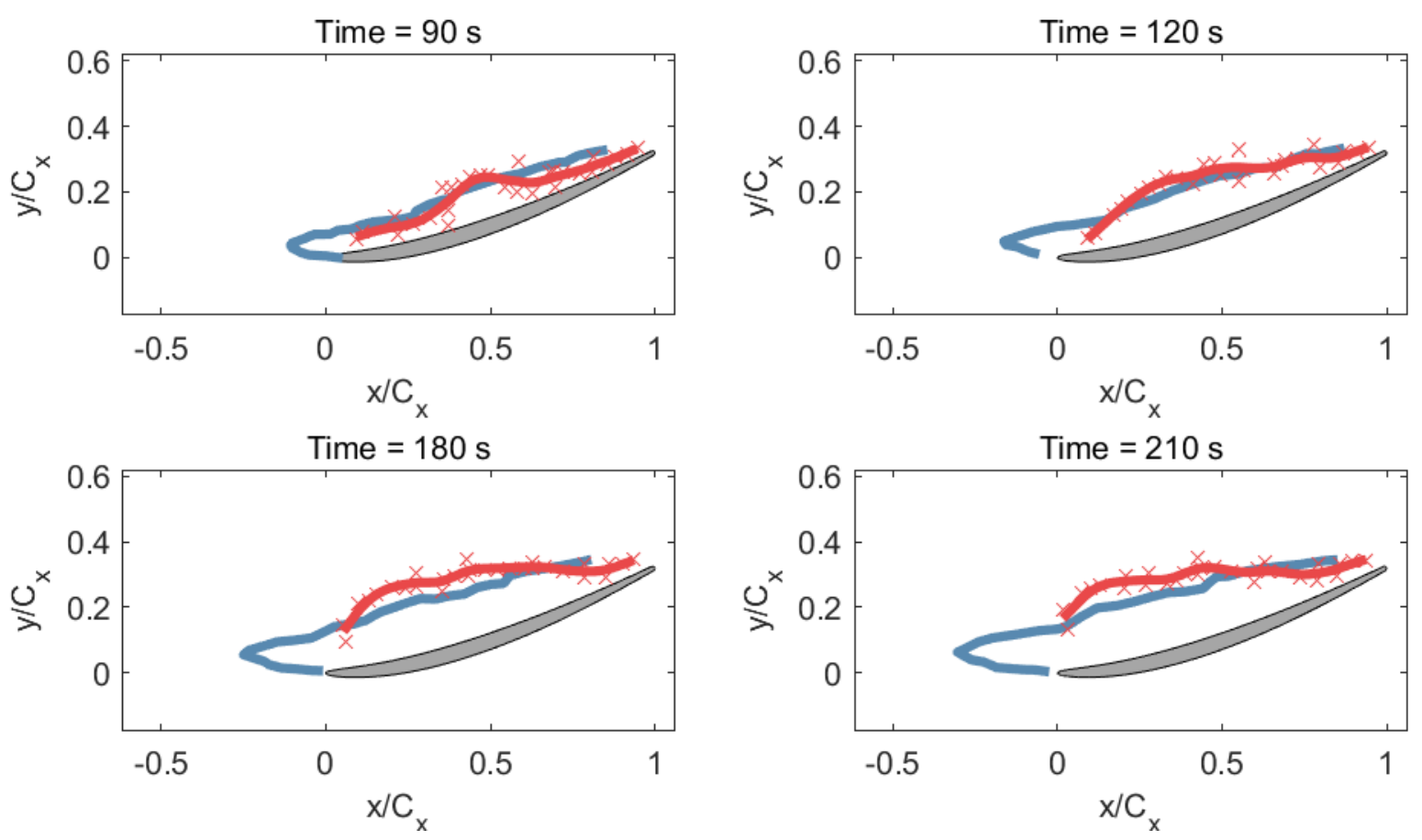

Fig. 15 Test \# 2: $0^{\circ}$ Angle of Attack. Side view camera data shown in blue, individual DIP node data in red crosses, and spanwise averaged DIP data shown in red line.
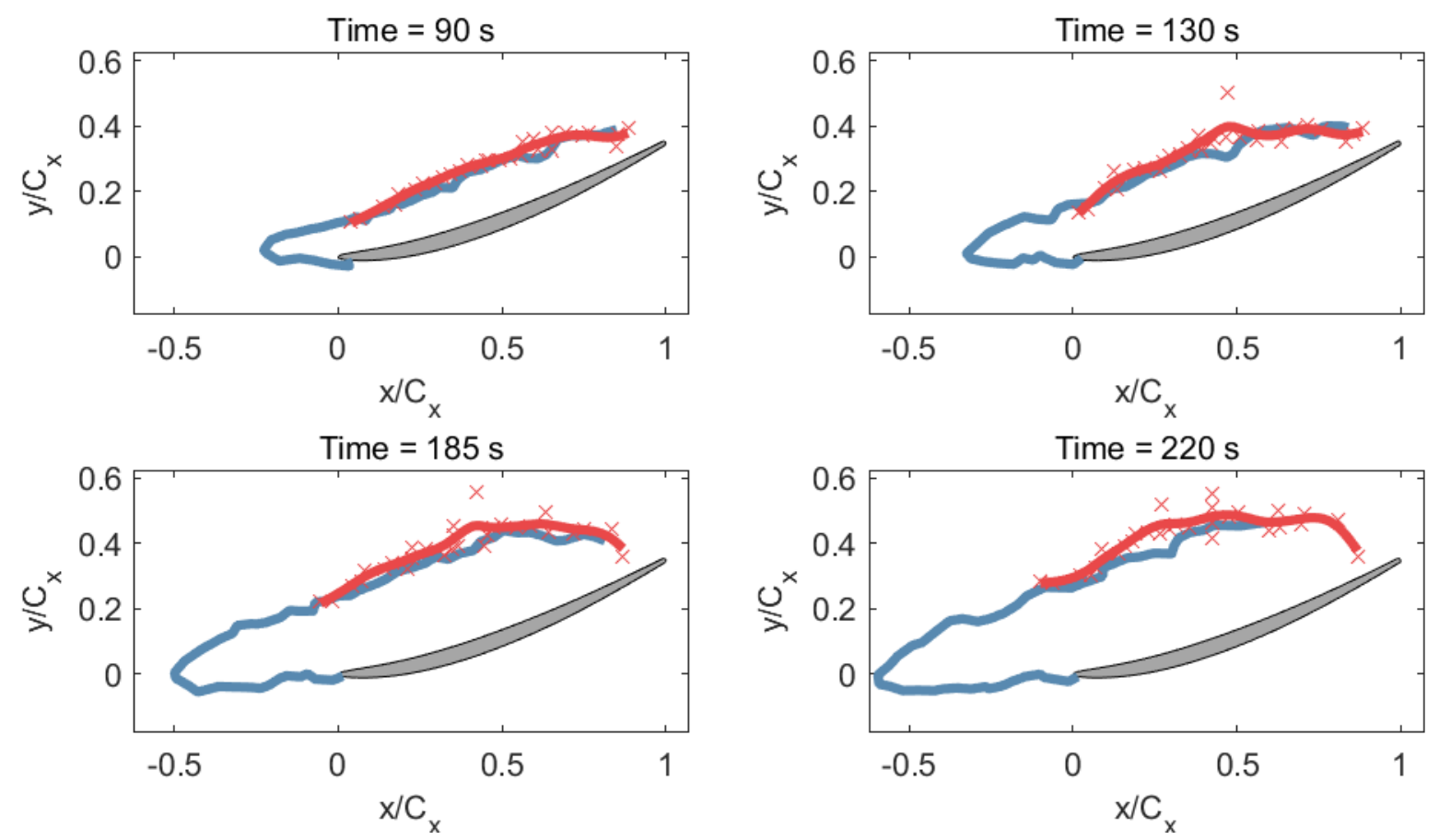

Fig. 16 Test \# 3: $+1.5^{\circ}$ Angle of Attack. Side view camera data shown in blue, individual DIP node data in red crosses, and spanwise averaged DIP data shown in red line. 


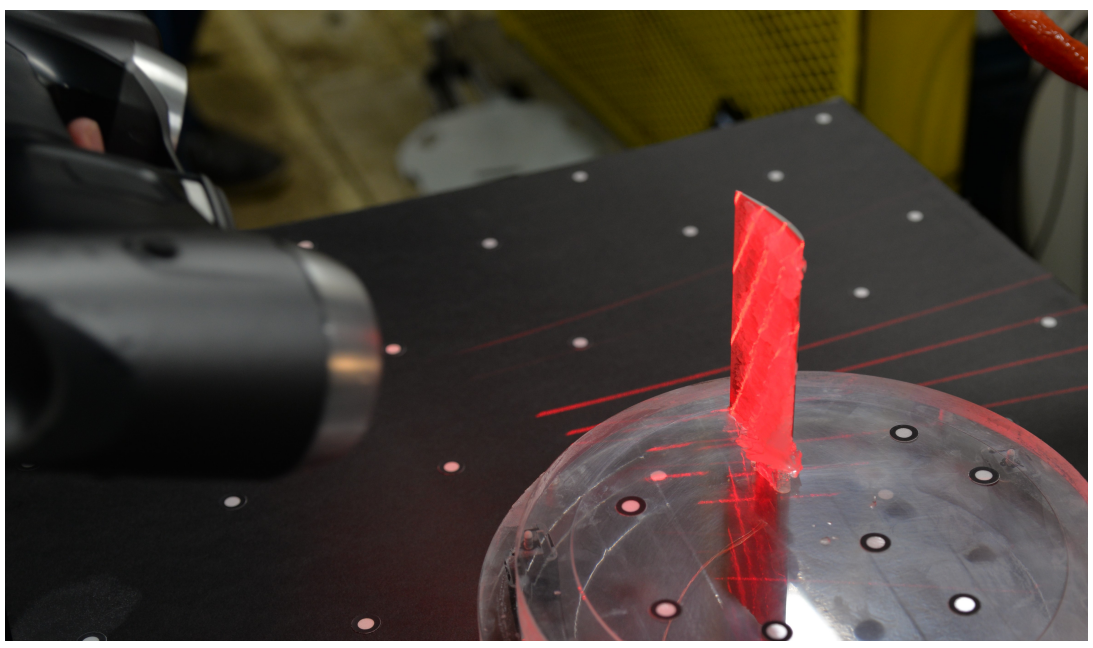

Fig. 17 Scanning of accreted ice using the Creaform HandyScan 7000.

it was decided to compare it to measurements taken with the Creaform HandyScan 7000. It has a rated accuracy of $0.025 \mathrm{~mm}$ for a part size in the range of 0.05-4 $\mathrm{m}$ [18]. The device uses a duel camera system with a single structured light source. The method of determining similarity between the two camera sets utilises targets (circular stickers) which are placed onto the object to be scanned and also uses natural features of the object being scanned, such as geometrical/colour texture. The device has poor performance when measuring glaze ice with with high transparency. To get the best results, the ice was treated with a low temperature gas to completely freeze out the ice in a non-equilibrium state leading to a surface finish more closely matching rime ice enhancing the reflectivity. The need to place targets and freeze out the ice structure meant it was not possible to measure the ice thickness during the accretion process. Instead, at the end of the test day the altitude chamber was re-pressurised to atmospheric pressure while maintaining sub freezing conditions $\left(\approx-10^{\circ} \mathrm{C}\right)$. It was then possible to remove the test article from the wind tunnel and complete the ice scan. The ice being scanned is shown in Fig. 17, and the results are shown in Fig. 18, where the HandyScan results are shown in the blue mesh, and the coarse mesh measurements are from the DIP system. Regions where the HandyScan mesh has no data was caused by insufficient reflectivity of the structured light source in that region.

Immediately before the test piece was removed for scanning, a final DIP measurement was taken (to account for any changes in accretion profile caused by sublimation and evaporation during the chamber re-pressurisation). The measured accretion profile via the side view camera and DIP is shown in Fig. 19 It should be noted that this test point had 240 seconds of accretion, meaning that the accretion profile in Fig. 19 was taken 365 seconds after ice off.

Few data points from the DIP match the side view data in Fig. 19, which based on the historical assumption of uniform thickness along the span, would suggest that the DIP had poor accuracy. However, comparing the DIP profile to the data from the Creaform HandyScan, as shown in Fig. 18, it can be seen that the DIP was able to predict the surface non-uniformities along the span axis. It was found that on average, that the deviation between the DIP dataset and the HandyScan normalised by the chord length was within 0.016. The DIP datapoints which match the side view camera dataset were nearest to the free end, showing that the side view had only detected the ice thickness on the free tip of the stator and not captured the average profile along the span of the blade.

To help visualise the span-wise variations, accretion profiles were extracted along the span axis at $25 \%, 50 \%$ and 75\% chord, as shown in Fig. 20. These profiles are shown in Fig. 21, where 0\% span is defined as the free end of the stator, and ice thickness is defined as the vertical height of the ice above the stator surface. These profiles show a general trend of there being a greater thickness of ice at the ends of the stator (free and fixed ends) compared to the mid-span. This matches the previous observation of there being enhanced accretion at the fixed end of the stator. At the free end, where a $20 \%$ span clearance gap existed between the tip and the other side wall, three dimensional flows occurred around the tip which could have led to enhanced accretion.

To minimise computational requirements, it was decided that this test campaign would primarily use a single camera, structured light source. For some tests, there was a secondary camera with a viewing angle different to that of the first camera. The cameras were calibrated using the same calibration piece and structured light source and produced two independent datasets. Figure 22 shows the accretion profile produced by averaging the two datasets, taken immediately 


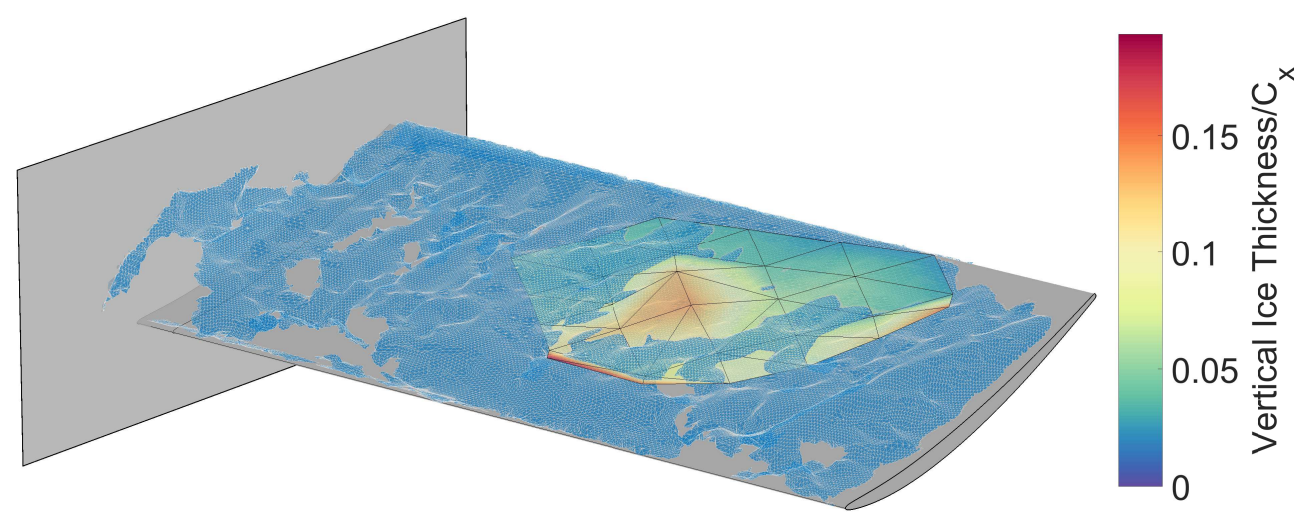

Fig. 18 Comparison of DIP and handheld scanner data.

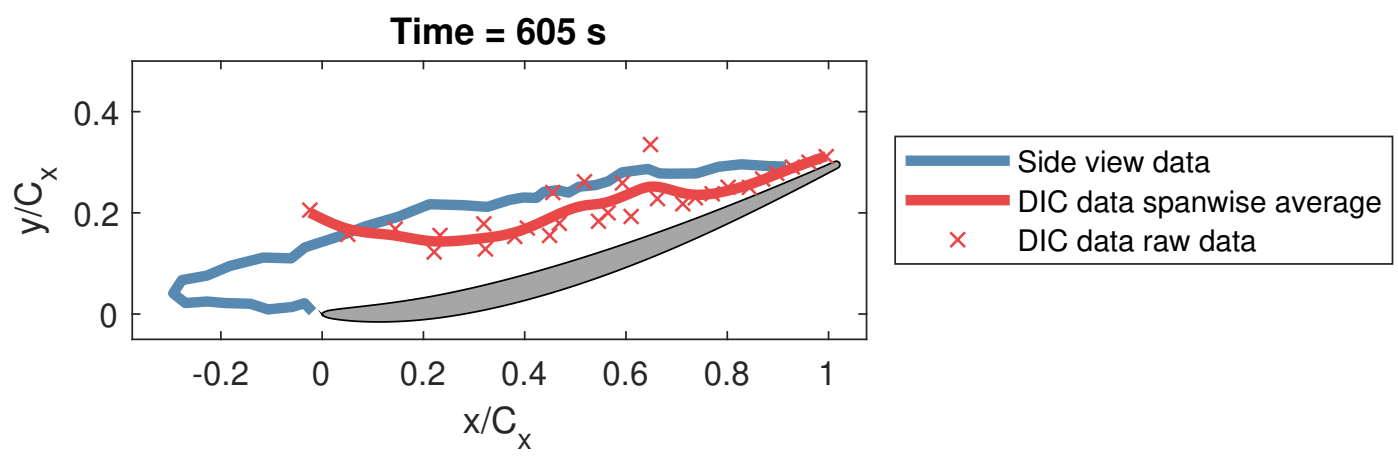

Fig. 19 Accretion profile measured by side view camera and DIP system. Data captured after ice off, immediately before the test piece was scanned with the Creaform HandyScan.

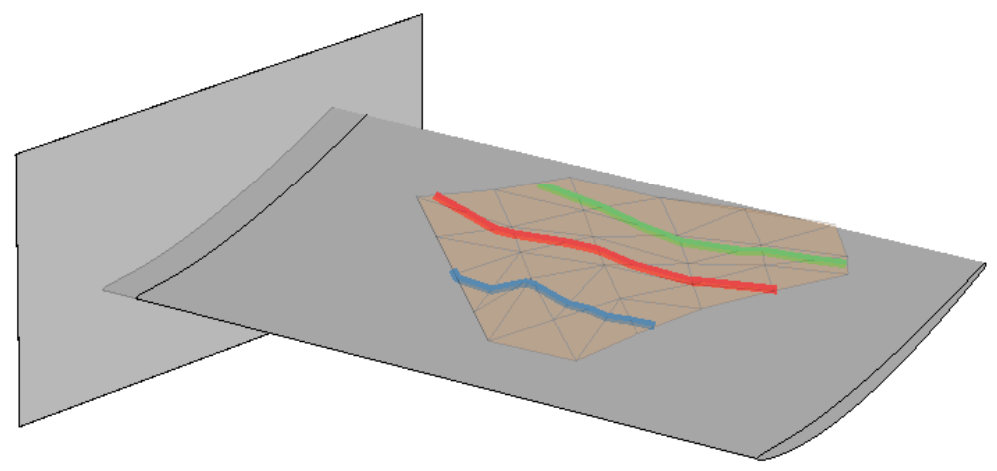

Fig. 20 Spanwise variation of ice thickness. 


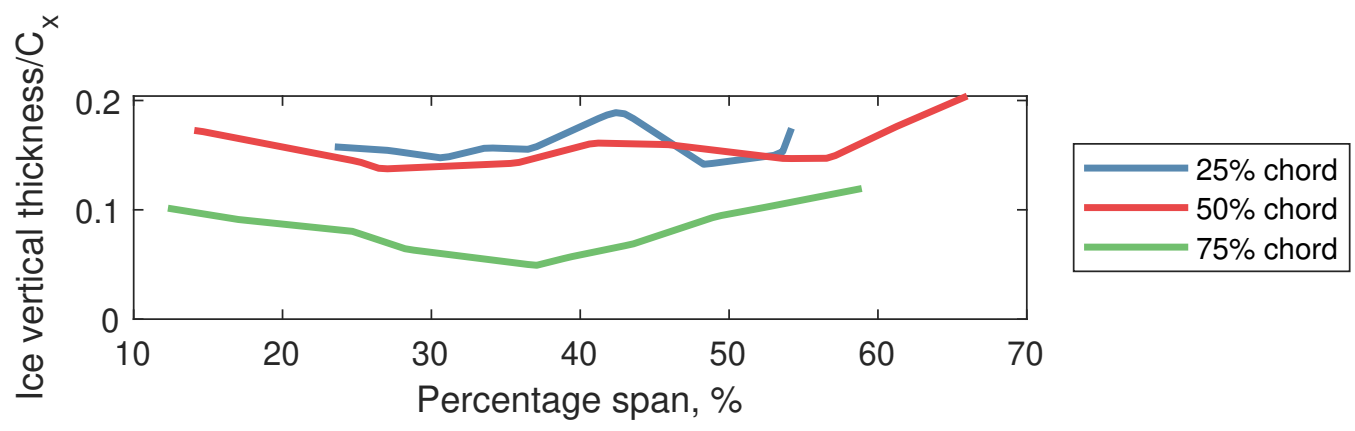

Fig. 21 Spanwise variation of ice thickness.

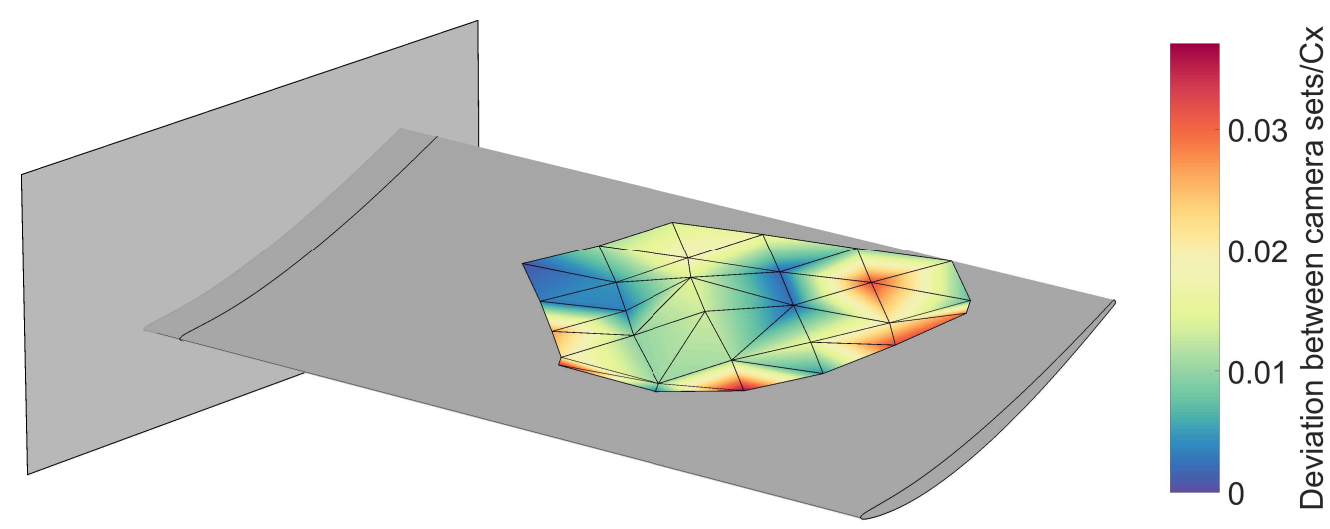

Fig. 22 Comparison of duel camera datasets.

before the test piece was removed for scanning. The colour of the profile is based on the deviation between the two DIP datasets. It can be seen that for the majority of the surface that deviation between each dataset (normalised by the chord length) was less than 0.02 , however there are some nodes with much greater deviation. The mean deviation normalised by the chord length was found to be 0.014 . Due to surface irregularities, the view of some nodes of the structured light source were optically blocked by surrounding ice peaks. Due to the semi-transparency of the ice, it was still possible to view the laser node, however the calibration will not have taken into account the diffraction of the light through the adjacent ice. As a result, this partially optically blocked node will have produced an inaccurate measurement, leading to high deviation between the dataset of each camera. By averaging the datasets of each camera, the DIP measurements had a mean deviation (normalised by the chord length) from the handheld scanner of 0.0085 , hence making the dataset more accurate compared to the single camera system.

\section{Conclusion}

The aim of this work was to determine the feasibility of measuring transient, three dimensional, ice crystal icing accretion profiles with use of a structured light source. The data from this system was compared to a backlit side view and also to a commercially available handheld scanner. The data showed that it is possible to determine accurate three dimensional profiles, which for this test piece allowed for span-wise variations to be captured. It was found that by using a duel camera system that the accuracy of the method could be improved compared to using a single camera, with the mean deviation between the DIP and handheld scanner (normalised by the axial chord length) being within 0.0085 . Given that a one pixel displacement led to a vertical displacement of the same order of magnitude as the quoted error, increased accuracy may be obtained by using cameras with increased pixel densities. Due to the findings of 
un-uniformities in accretion of finite span accretion blades, two dimensional models of such geometries may need to be re-validated by averaged profiles of three dimensional measurements to remove the end wall effects. Future work will go into coupling the data from both cameras, such that stereoscopic imaging can be utilised, hopefully further improving the accuracy of the method.

\section{Acknowledgements}

The authors would like to thank Rolls-Royce Plc for funding the research; the UK Engineering and Physical Sciences Research Council (EPSRC) for the CDT in Gas Turbine Aerodynamics studentship; Rolls Royce design and make graduate team for the design of the first generation DIP set-up; and Innovate UK for contributions towards the costs of experimental testing. Thanks also go to the staff of the NRC in scoping and conducting the tests, with a very special thanks to Neuteboom.

\section{References}

[1] Mason, J., Strapp, W., and Chow, P., "The Ice Particle Threat to Engines in Flight," 44th AIAA Aerospace Sciences Meeting and Exhibit, 2006. https://doi.org/10.2514/6.2006-206.

[2] Grzych, M., and Mason, J., "Weather Conditions Associated with Jet Engine Power Loss and Damage Due to Ingestion of Ice Particles: What We've Learned Through 2009," 14th Conference on Aviation, Range, and Aerospace Meteorology, 2010. URL http://www.wxforecastnow.com/documents/grzych\{_\}ams\{_\}2010.pdf.

[3] Bravin, M., and Strapp, J. W., "A Continuing Investigation of Diurnal and Location Trends in an Ice Crystal Icing Engine Event Database,” SAE Technical Papers, Vol. 2019-June, No. June, 2019, pp. 90-105. https://doi.org/10.4271/2019-01-1964

[4] Oliver, M. J., "Validation Ice Crystal Icing Engine Test in the Propulsion Systems Laboratory at NASA Glenn Research Center," 6th AIAA Atmospheric and Space Environments Conference, ????, pp. 1-34.

[5] Veres, J. P., Jorgenson, P. C. E., Nili, S., Bommireddy, S. R., and Suder, K. L., “ANALYSIS OF THE HONEYWELL UNCERTIFIED RESEARCH ENGINE ( HURE )," 2019.

[6] Currie, T., Struk, P., Tsao, J.-C., Fuleki, D., and Knezevici, D., "Fundamental Study of Mixed-Phase Icing with Application to Ice Crystal Accretion in Aircraft Jet Engines," 4th AIAA Atmospheric and Space Environments Conference, 2012. https://doi.org/10.2514/6.2012-3035.

[7] Struk, P. M., King, M. C., Bartkus, T. P., Tsao, J.-C., Fuleki, D., Neuteboom, M., and Chalmers, J., "Ice Crystal Icing Physics Study using a NACA 0012 Airfoil at the National Research Council of Canada's Research Altitude Test Facility," 2018 Atmospheric and Space Environments Conference, 2018. https://doi.org/10.2514/6.2018-4224. URL https://arc.aiaa.org/doi/10.2514/6.2018-4224

[8] Bucknell, A., Mcgilvray, M., Gillespie, D. R. H., Jones, G., and Reed, A., "Experimental Studies of Ice Crystal Accretion on an Axisymmetric Body at Engine-Realistic Conditions," 2018 Atmospheric and Space Environments Conference, AIAA AVIATION Forum, (AIAA 2018-4223), 2018.

[9] Bucknell, A., Mcgilvray, M., Gillespie, D. R. H., Jones, G., and Collier, B., "Experimental Study and Analysis of Ice Crystal Accretion on a Gas Turbine Compressor Stator Vane," Submitt. SAE Int. Conf. Icing Aircraft, Engines Struct. June 17-21, Minneapolis, MN, USA, 2019., 2019. https://doi.org/10.4271/2019-01-1927.

[10] Currie, T. C., Fuleki, D., Knezevici, D. C., and MaCleod, J. D., “Altitude Scaling of Ice Crystal Accretion," 5th AIAA Atmospheric and Space Environments Conference, 2013, pp. 1-26. https://doi.org/10.2514/6.2013-2677. URL http://arc.aiaa. org/doi/10.2514/6.2013-2677.

[11] Salvi, J., Fernandez, S., Pribanic, T., and Llado, X., "A state of the art in structured light patterns for surface profilometry," Pattern Recognition, Vol. 43, No. 8, 2010, pp. 2666-2680. https://doi.org/10.1016/j.patcog.2010.03.004. URL http://dx.doi.org/ 10.1016/j.patcog.2010.03.004

[12] Zhang, K., Wei, T., and Hu, H., "An experimental investigation on the surface water transport process over an airfoil by using a digital image projection technique," Experiments in Fluids, Vol. 56, No. 9, 2015, pp. 1-16. https://doi.org/10.1007/s00348-0152046-z

[13] Gao, L., Veerakumar, R., Liu, Y., and Hu, H., "Quantification of 3D Ice Structures Accreted on a Wind Turbine Airfoil Model," SAE Technical Papers, Vol. 2019-June, No. June, 2019, pp. 1-7. https://doi.org/10.4271/2019-01-2030. 
[14] Mason, J. G., Chow, P., and Fuleki, D. M., "Understanding Ice Crystal Accretion and Shedding Phenomenon in Jet Engines Using a Rig Test," Journal of Engineering for Gas Turbines and Power, 2011. https://doi.org/10.1115/1.4002020

[15] Knezevici, D. C., Fuleki, D., and MacLeod, J., "Development and Commissioning of a Linear Compressor Cascade Rig for Ice Crystal Research,” 2011. https://doi.org/10.4271/2011-38-0079, URL http://papers.sae.org/2011-38-0079/

[16] Struk, P., Currie, T., Wright, W. B., Knezevici, D. C., Fuleki, D., Broeren, A., Vargas, M., and Tsao, J.-C., "Fundamental Ice Crystal Accretion Physics Studies,” 2011. https://doi.org/10.4271/2011-38-0018

[17] Bucknell, A., McGilvray, M., Gillespie, D., Yang, X., Jones, G., and Collier, B., "ICICLE: A Model for Glaciated \& Mixed Phase Icing for Application to Aircraft Engines," SAE Technical Paper Series, Vol. 1, 2019, pp. 1-19. https://doi.org/10.4271/2019-011969

[18] “HandyScan 3D,”, 2020. URL https://www.creaform3d.com/en/portable-3d-scanner-handyscan-3d 